\title{
Morfologia da glândula mamária do quati (Nasua nasua) ${ }^{1}$
}

\author{
Juliana B. Casals ${ }^{2 *}$, Celina A. Mançanares², Naira C.G. Pieri² ${ }^{2}$ Maria A. Miglino ${ }^{3}$, \\ Carlos E. Ambrósio ${ }^{2,3}$ e Ana F. Carvalho ${ }^{4}$
}

\begin{abstract}
Casals J.B., Mançanares C.A., Ambrósio C.E., Miglino M.A., Pieri N.C.G. \& Carvalho A.F. 2013. [Morphology of mammary gland of the coati (Nasua nasua).] Morfologia da glândula mamária do quati (Nasua nasua). Pesquisa Veterinária Brasileira 33(11):13711378. Departamento de Ciências Morfológicas, Centro Universitário da Fundação de Ensino Octávio Bastos, Av. Doutor Octávio Bastos s/n, Jardim Nova São João, São João da Boa Vista, SP 13874-148, Brazil. E-mail: ceambrosio@usp.br

Coati is an omnivorous animal, found throughout of Brazil. The reproduction of this species occurs only once a year during spring. Females are matriarchs and nurse their young until 5 months old, living with their young in groups of up to 30. For morphological description of the mammary gland Nasua nasua six animals were used coming from the hatchery Scientific (Cecrimpas), Unifeob. Authorized by IBAMA (Proc. 02027.002322/9899). For the macroscopic analysis one animal was injected with neoprene latex, was injected into the femoral artery with red latex and the jugular vein with blue colored one. The others animals were fixed in a $10 \%$ aqueous solution of formaldehyde. For microscopic analysis, glandular fragments were collected and submitted to routine process, embedded in paraffin and stained with hematoxylin and eosin, toluidine blue and picrossirius. Macroscopically were evidenced three pairs of mammary glands, two pairs positioned in the abdominal region and one pair in the inguinal region. Microscopically, was found a simple epithelium lining external mammary papillae, keratinized stratified epithelium, which continued throughout the gland. At the entrance of the papillae ostium the epithelium of the epidermis was modified occurring a transition from stratified epithelium to cubical epithelium into the papillary duct. The glandular parenchyma was characteristically alveolar with secretory cells observed predominantly in the lactating female. The macroscopic and microscopic results are similar to those already described in bitches (Cannis familiaris) and Procyon cancrivorus belonging to the same family of coati, the family Procyonidae.
\end{abstract}

INDEX TERMS: Coati, Nasua nasua, mammary gland, mammary papilla.

RESUMO.- Nasua nasua é um animal onívoro, encontrado em todo Brasil. A reprodução da espécie ocorre somente uma vez ao ano, na primavera. As fêmeas são matriarcas e amamentam suas crias até os 5 meses de idade, vivem

\footnotetext{
${ }^{1}$ Recebido em 25 de julho de 2013.

Aceito para publicação em 5 de dezembro de 2013.

${ }^{2}$ Laboratório de Morfofisiológica Molecular do Desenvolvimento, Departamento de Medicina Veterinária (DMV), Av. Duque de Caxias Norte 225, Campus da Universidade de São Paulo (USP), Pirassununga, SP 13635-900, Brasil. *Autor para correspondência: ceambrosio@usp.br

${ }^{3}$ Setor Anatomia dos Animais Domestico e Silvestres, Departamento de Cirurgia, Av. Prof. Dr. Orlando Marques de Paiva 87, Cidade Universitária, São Paulo, SP 05508-70, Brasil.

${ }^{4}$ Curso de Medicina Veterinária, Centro Universitário da Fundação de Ensino Octávio Bastos (Unifeob), Av. Dr. Octavio Bastos 249, Jardim Nova São João, São João da Boa Vista, SP 13874-000, Brasil.
}

com seus filhotes em bandos de até 30 indivíduos. Para descrição morfológica da glândula mamaria do Nasua nasua foram utilizados seis animais provenientes do Criatório Cientifico (Cecrimpas), Unifeob. Autorizado pelo Ibama (Proc.02027.002322/98-99). Para análise macroscópica um animal foi injetado com látex neoprene, sendo a artéria femoral injetada com látex de cor vermelha e a veia jugular de cor azul. Os demais animais foram fixados em solução aquosa a $10 \%$ de formaldeído. Para análise microscópica, fragmentos glandulares foram coletados e submetidos ao processo rotineiro, embebido em parafina e corados com Hematoxilina e Eosina, Picrossírius e Azul de Toluidina. Macroscopicamente foram evidenciados três pares de glândulas mamárias, sendo dois pares posicionados na região abdominal e um par na região inguinal. Microscopicamente, notou-se epitélio de revestimento externo das papilas 
mamárias, epitélio pavimentoso estratificado queratinizado, o qual seguia por toda glândula de forma irregular. $\mathrm{Na}$ entrada do óstio, o epitélio da epiderme era modificado ocorrendo uma transição de epitélio pavimentoso estratificado para um epitélio cúbico no ducto papilar. 0 parênquima glandular era caracteristicamente túbulo alveolar com células secretoras, evidenciado principalmente no animal lactente. Os resultados macroscópicos e microscópicos assemelham-se aos já descritos nas cadelas (Canis familiaris) e os do Procyon cancrivorus pertencente à mesma família do quati, Família Procyonidae.

TERMO DE INDEXAÇÃO: Glândula mamária, quati, Nasua nasua, carnívoros, papila mamária.

\section{INTRODUÇÃO}

O quati é um animal da ordem Carnívora e da família Procyonidae, com ampla distribuição pela America do Sul. É um animal de porte médio; podendo atingir até $11 \mathrm{~kg}$ e obter uma ninhada por ano (Gompper 1995, Zeller 1999, Beisiegel 2001, Rocha et al. 2006). Os estudos comportamentais realizados por Russel (1996) e Gompper (2004) descrevem que as fêmeas são matriarcais e vivem com seus filhotes em grupos de 30 indivíduos e estes são amamentados até os cinco meses (Beisiegel 2001). Favaron et al. (2008) descreveram as glândula pineal; Pieri et al.(2011) a dentição e Santos et al. (2010) os músculos do ombro, braço e antebraço do quati e estes autores evidenciaram que este animal apresenta características morfológicas, similares aos cães, por filogeneticamente terem um ancestral comum.

As glândulas mamárias são estruturas apócrinas modificadas, em fêmeas estas glândulas apresentam respostas variadas aos hormônios esteroides, esta interação ocorre de forma complexa, via autócrina, parácrina e endócrina (Humphrey \& Estes 1979, Chamness et al. 1980).

Estudos com cães relatam que os hormônios promovem mudanças morfológicas na glândula mamária canina durante o ciclo estral (Rehm et al. 2007, Santos et al.2009, Chandra et al. 2010). Em cães da raça beagle, Chandra et al. (2010) descreveram que as glândulas mamarias sofrem alterações morfológicas cíclicas relacionadas ao ciclo ovariano, principalmente nos lóbulos- alveolares, tecido glandular e epitélio. Em ratos, o epitélio mamário responde a mudanças cíclicas nos níveis hormonais ovarianas, com pequenas mudanças na morfologia glandular (Schedin et al. 2000).

Alguns estudos morfofuncionais da glândula mamária foram descritos em animais silvestres e domésticos (Luiz et al. 2004, Samoto et al. 2006, Santos et al. 2007, Bellatine et al. 2010), desta forma, o conhecimento deste órgão é baseado na função e mudanças morfológicas. Entretanto, Ellenport (2000) e Silver (1966) classificam as glândula mamarias nos carnívoros domésticos de acordo com a localização. Portanto os autores citam que os carnívoros domésticos há desenvolvimento de cinco pares de glândulas mamarias, embora quatro ou seis pares têm sido encontrados em alguns animais. Nos cães existem dois pares de glândulas torácica (M1 e M2), 2 abdominal (M3 e M4), e um inguinal (M5).

Bellatine et al. (2010) estudando a família Procyonidae, relataram que as fêmeas de Procyon cancrivorus possuem três pares destas, sendo um par abdominais craniais, um par abdominais caudais e um par de inguinais. Contrapondo, em marsupiais estas glândulas estão localizadas na região abdominal caudal, possuindo um formato de ferradura, e as papilas mamarias são em forma de 'U' e número de 11 dispostas em pares, exceto uma localizada centralmente (Samoto et al. 2006).

Histologicamente nos animais domésticos a glândula mamaria tem o lúmen delimitado por uma camada interna de células epiteliais polarizadas que as dividi em duas camadas externas das células epiteliais e mioepiteliais, estas exibem características de células fusiformes alongadas (Ramalho et al. 2006, Beha et al. 2012). Tanto as células basais e mioepiteliais sintetizam a membrana basal dos ductos e alvéolos, e formar uma barreira estrutural entre as células epiteliais luminais e o estroma circundante (Polyak et al. 2005).

De acordo com Sorenmo et al. (2011) os alvéolos não secretor são semelhantes a pequenos ductos e as células secretoras alveolares variar de cubóide para colunar. 0 epitélio é rodeado por uma membrana basal e seus componentes são suportados por tecido mesenquimal, tecido conjuntivo fibroso, tecido adiposo, vasos sanguíneos, nervos e vasos linfáticos. A quantidade de tecido adiposo e mamário presente é muito variável e é mais abundante nas glândulas abdominal e inguinal do que nas glândulas torácicos.

De acordo com Luiz et al. (2004) por meio da técnica de ultrassonografia e macroscópica em cães as glândulas mamarias são irrigadas na porção cranial pela artéria epigástrica cranial superficial se origina da A. torácica interna e subclávia, e pela porção caudal pela A. epigástrica caudal superficial que origina da A. ilíaca externa e tronco pudendo epigástrico. Estas duas artérias endereçam ramos para as mamas e papilas mamárias.

Portanto, o quati é um animal encontrado em todo território brasileiro, entretanto a literatura cientifica relacionada sobre a morfológica deste é escassa. Isto também é valido para a glândula mamaria, uma vez que a maioria dos artigos relacionados a glândula mamaria discuti o aspecto oncológico desta em animais domésticos. Contudo, o presente artigo visa investigar e caracterizar morfologicamente a glândula mamaria de Nasua Nasua, visando discutir os resultados obtidos com outras espécies e contribuir para estudos futuros sobre família a Procyonidae.

\section{MATERIAL E MÉTODOS}

Para esta pesquisa, seis fêmeas adultas de Nasua nasua foram utilizados, sendo um em fase de lactação. Todos os animais eram provenientes do Criatório Científico (Cecrimpas)-, Unifeob, São João da Boa Vista, São Paulo, Brasil. (Processo IBAMA 02027.00286/0492). Os animais foram eutanasiados, recebendo Telazol® (Telazina + Zolazepan) na dose de $20 \mathrm{mg} / \mathrm{kg}$, intramuscular e posteriormente, $10 \mathrm{ml}$ de Cloreto de potássio a $10 \%$, intravenosos (IV) Conforme os princípios éticos na utilização de animais para fins de Pesquisa, Didática e Clínica (Adaptado pelos termos do Colégio Brasileiro de Experimentação Animal - Cobeas).

Um dos animais designado para análise macroscópica, após ortotanásia, foi injetado com látex neoprene corado com vermelho na artéria femural, e corado com azul a veia jugular, ambos utilizando cânula $25 \times 7$, para posterior dissecação e observação 
dos principais ramos arteriais e venosos da glândula mamária. Os outros animais foram fixados com formol a $10 \%$ por perfusão da artéria jugular, por 2 horas e seguida de imersão, de acordo com Sousa (2003). As glândulas mamarias foram dissecadas e investigadas por microscopia de luz.

Os fragmentos foram fixados em formol 10\%, desidratados em séries de etanol em concentrações crescentes de 70\% a 100\%, diafanizados e embebidos em parafina (Histoses Merck) (Behmer 1976, Tolosa et al. 2003). Posteriormente cortados em micrótomo (Leica RM 2165), com espessura $5 \mu \mathrm{m}$ e corados por picrossírius não polarizado segundo Junqueira et al. (1979) hematoxilina-eosina e azul de toluidina segundo Gerrits (1983). Também foram submetidos à reação de histoquímica de PAS, àcido periódico de Shiff com fundo de hematoxilina de Harris segundo Lillie \& Fulmer (1976). Todo material foi investigado com auxílio de máquina Sony Mavica 3.2 Mp e a fotomicrográficas em um Fotomicroscópio Leica DM 2000.

As glândulas mamárias e papilas foram submetidas à pesagem, mensuradas (circunferência da base da papila) e o volume foi obtido por meio de imersão em proveta com água, segundo Arquimedes.

\section{RESULTADOS}

A análise macroscópica, os cinco animais, apresentam três pares de glândulas mamárias, sendo duas na região abdominal cranial, duas na região abdominal caudal e duas na região inguinal, entretanto um animal foi evidenciado um par de glândulas a mais, na região torácica caudal (Fig.1).

A glândula mamária do animal lactente apresentava na região glandular aumento na pigmentação, poucos pêlos, formato cônico e pendular, diferentemente as glândulas mamarias das fêmeas não lactentes região glandular era menor, sem pigmentação e formato arredondado (Fig.1B,C).

A cadeia mamária destes animais estava inserida anatomicamente nos músculos: peitoral profundo (porção abdominal), músculo oblíquo externo do abdome, músculo reto do abdome e parte no músculo grácilis. Quanto à análise da vascularização, observou-se que a veia e artéria epigástrica superficial cranial e veia e artéria epigástrica superficial caudal (Fig.2).

Histologicamente a epiderme era constituída por um epitelial estratificado pavimentoso queratinizado, a derme era composta por tecido conjuntivo frouxo e denso não modelado. A derme, na porção média e proximal da papila mamária evidenciou-se a presença de glândulas sebáceas associadas a folículos pilosos e glândulas sudoríparas tubulares enoveladas dispersas. 0 óstio papilar era revestido por epitélio pavimentoso estratificado queratinizado, da mesma forma que à papila mamaria. Na entrada do óstio, o epitélio da epiderme era modificado, o qual encontrava-se em transição para epitélio cúbico simples no ducto papilar (Fig.3).

A papila mamária possuía uma região ricamente vascularizada e com a presença fibras musculares lisas circulares e transversas, sendo que a sua maioria estavam localizadas abaixo do epitélio queratinizado. A disposição destas fibras podem funcionar como músculo esfíncter papilar nestes animais. E estas camada não circundava individualmente cada óstio. Foram observados em média, cinco óstio papilares o que conferia aspecto de peneira (Fig.3).

O parênquima glandular era caracteristicamente túbu- lo alveolar com células secretoras, evidenciadas principalmente no animal em lactação. As células secretoras apresentavam núcleo grande e redondo, citoplasma glandular e encontrava-se apoiada sobre uma camada delgada e tecido conjuntivo ricamente vascularizado. Estas formavam o epitélio cuboide. Nos animais não lactentes, observou-se a ausência de funcionalidade das glândulas túbulo alveolares, uma vez que estas apresentavam hipotrofiadas. Os vasos e capilares em todos os animais, encontravam-se posicionados entre os dois epitélios de cada alvéolo e mantinham-se próximo as células secretoras (Fig.3).

As papilas mamárias de seis fêmeas de Nasua nasua foram mensuradas e estes não apresentaram diferença significante (Quadro 1). Entretanto, o elevado desvio padrão e média observado no volume, peso e circunferência das glândulas, está relacionado ao animal lactente, pois este apresentou aumento nos parâmetros mensurados, quando comparado com os animais não latente.

\section{DISCUSSÃO}

De acordo com este estudo o quati apresenta a glândula mamaria com algumas características morfológicas similares ao cão doméstico e aos animais pertencentes a família procyonidae. Bellatine et al. (2010) pesquisou os animais da mesma família que o quati, e afirma que anatomicamente as fêmeas de Procyon cancrivorus possuem três pares de glândulas mamárias, da mesma forma que os observados neste estudo no quati. Entretanto, a variação anatômica entre os indivíduos deve ser considerada, uma vez que um dos animais analisados neste estudo apresentou quatro pares de glândulas. Ellenport (2000) também menciona uma variação no número de glândulas mamarias nos animais domésticos

Assim, quando comparamos a disposição e números de pares de glândulas mamarias do quati com os carnívoros domésticos, notou-se que estes diferem em número, pois segundo Orr (1986), Dyce et al. (1997) \& Ellenport (2000), estes animais apresentam normalmente cinco pares de glândulas mamarias, sendo dois pares de glândulas torácica (M1 e M2), dois pares abdominal (M3 e M4), e um inguinal (M5).

Neste estudo notou-se uma diferença anatômica no formato nas papilas mamarias dos animais lactantes e não lactantes, as glândulas dos animais lactantes apresentavam-se cônica e pendular, entretanto das fêmeas não lactantes eram arredondadas, da mesma forma que observado por Dyce et al. (1997) nos animais domésticos e Arce \& Flechtman (1979), Jainudeen \& Hafez (1988) e Shida et al. (2001) em ratos, que utilizaram animais em diferentes fases de atividade glandular.

A cadeia mamária do quati encontram vascularizada pela veia e artéria epigástrica superficial cranial e veia e artéria epigástrica superficial caudal, semelhantes aos descritos por Dyce et al. (1997) e Luiz et al. (2004), em cães, segundo os autores neste animais a glândula mamarias são irrigadas pela artéria epigástrica cranial superficial se origina da A. torácica interna e subclávia, e pela porção caudal pela A. epigástrica caudal superficial que origina da A. ilíaca externa e tronco pudendo epigástrico.

Segundo Bellatini (2010) no mão pelada, Banks (1992) 
nos animais domésticos (cão) e Samoto et al. (2006) em marsupiais, histologicamente a papila mamária é revestida externamente pelo epitélio pavimentoso estratificado queratinizado e a derme papilar, constituída por tecido conjuntivo frouxo e denso não modelado, entremeadas de fibras musculares à derme reticular, igualmente observado no quati, entretanto também notou-se a presenças na porção média e proximal da papila mamária a presença de glândulas sebáceas associadas a folículos pilosos e glândulas sudoríparas tubulares enoveladas.
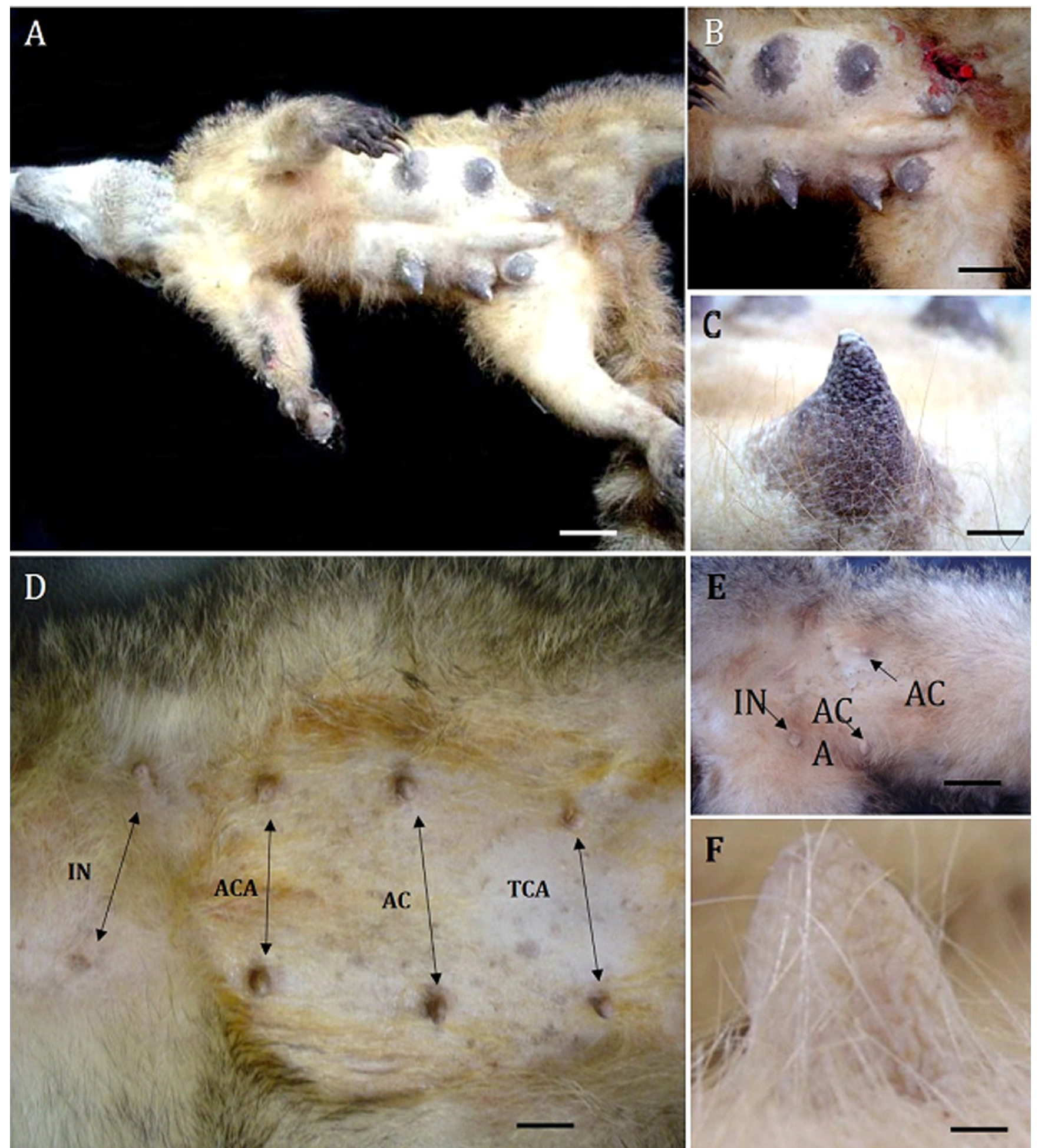

Fig.1. Região abdominal de fêmeas de Nasua nasua. (A,B) Fêmea lactente. (C) Animal lactente, papilas pigmentadas com formato cônico e pendular. (D,E) Fêmeas não lactentes, com quatro pares de glândulas. Glândula mamária abdominal cranial (AC), glândula mamária abdominal caudal e cranial (ACA e AC) e glândula mamária inguinal (IN). (F) as papilas mamárias sem pigmentação com formato arredondado e menor. 
Diferentemente das outras espécies de animais domésticos descritos por Gurther et al. (1987) \& Cowan (1989), nos animais analisados neste estudo o epitélio não adentrava o óstio papilar. Este era revestido por epitélio pavimentoso estratificado queratinizado, da mesma forma que à papila mamaria. Na entrada do óstio, o epitélio da epider- me era modificado, o qual encontrava-se em transição para epitélio cúbico simples no ducto papilar.

Banks (1992), Gaona et al. (1999) descrevem que nos animais domésticos o parênquima glandular é túbulo alveolar com células secretoras, entretanto no quati esta característica foi mais evidente nos animais lactantes. Contudo,
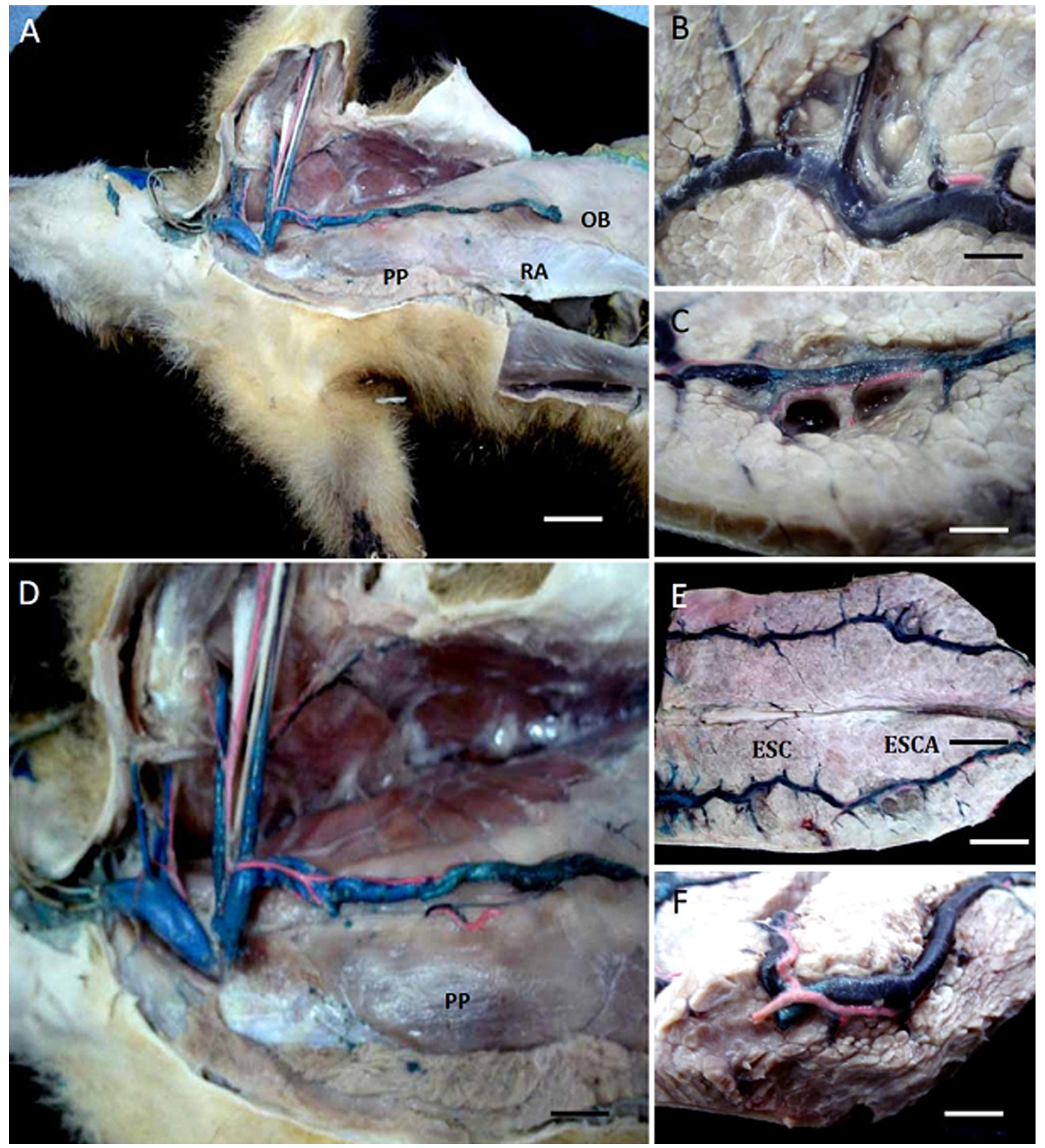

Fig.2. (A) Região muscular de inserção da cadeia mamária. Músculo peitoral profundo (PP); músculo reto abdominal (RA) e músculo oblíquo externo do abdome (OB). (B-D) Irrigação da cadeia mamaria, inter-relação entre a veia (V) e artéria (A) epigástricas superficiais caudais no parênquima glandular. (E,F) Veia epigástrica superficial cranial (ESC) que está sobreposta à artéria epigástrica superficial cranial e, a veia epigástrica superficial caudal (ESCA) que também está sobreposta à sua respectiva artéria. 

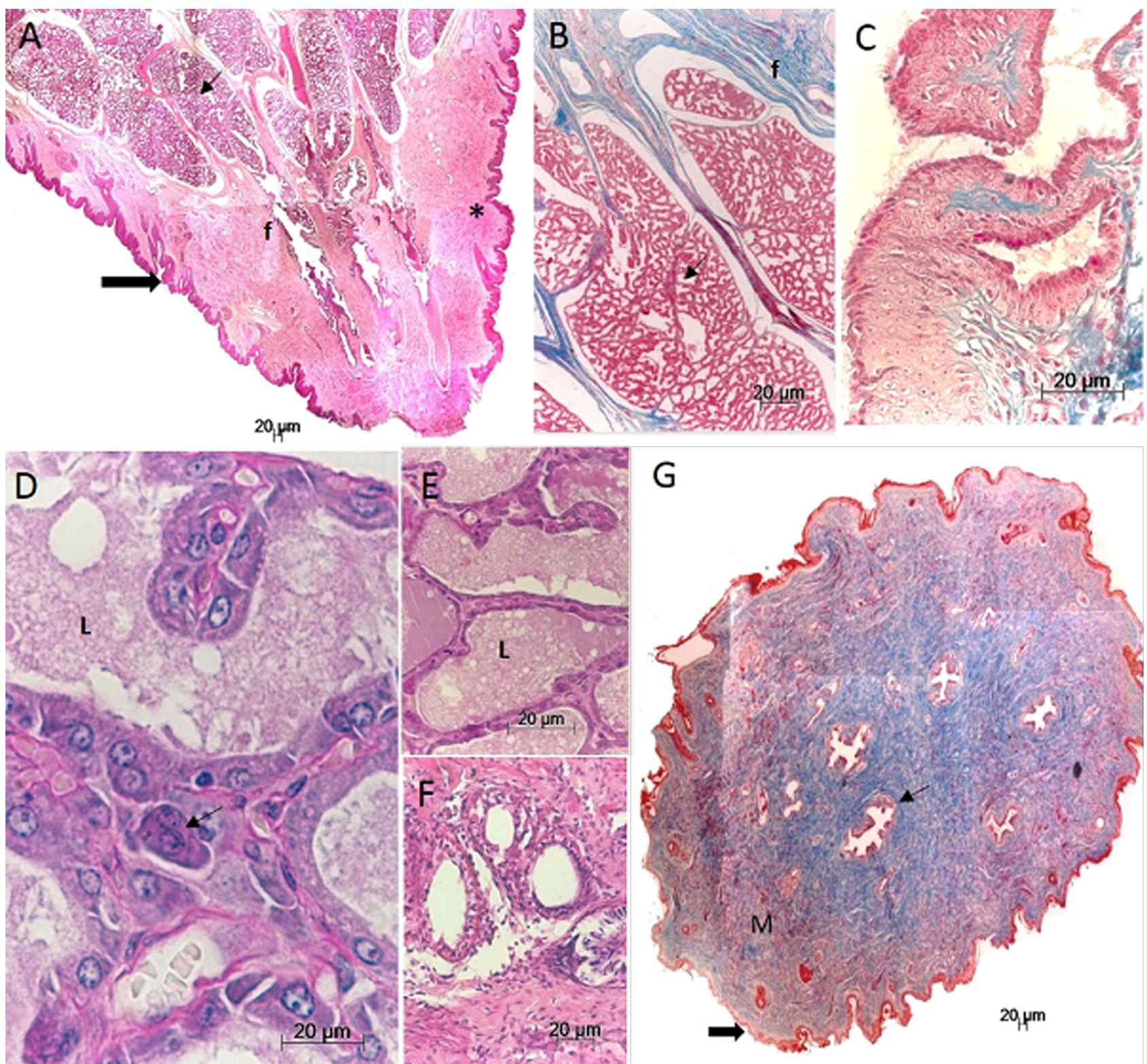

Fig.3. Glândulas mamarias da fêmea de quati. (A,B) Epitélio estratificado pavimentoso queratinizado (epiderme) (seta grossa), tecido conjuntivo denso não modelado com fibras musculares lisas, transversais entremeadas $\left({ }^{*}\right)$, tecido conjuntivo frouxo (f) (derme), parênquima glandular (seta). (C) Notar a transição do epitélio estratificado pavimentoso (seta vazia) para simples cúbico do ducto papilar (seta). (D,E) Notar que esta glândula estava em plena atividade secretora, com produto de secreção (L) no interior dos alvéolos e dois núcleos, indicando alta atividade de síntese (seta). (F) Observar a ausência de atividade das células glandulares do animal não lactente. (G) Epitélio pavimentoso estratificado (seta cheia), óstio papilar (seta), músculo liso circular periférico (M). Tricromo de Masson, reação de histoquímica de PAS, HE, Barra = 20 $\mu$ m.

Quadro 1. Resultados obtidos (médias e desvio padrão) das mensurações das papilas e glândulas mamárias de Nasua nasua. Animal lactente e não lactentes

\begin{tabular}{lccc}
\hline & GMACr $^{\mathrm{a}}$ & $\mathrm{GMAC}^{\mathrm{b}}$ & $\mathrm{GMI}^{\mathrm{c}}$ \\
\hline Volume da glândula (ml) & $23,9 \pm 24,5$ & $23,9 \pm 24,4$ & $20,1 \pm 19,3$ \\
Peso da glândula (g) & $10,2 \pm 12,1$ & $11,5 \pm 14,9$ & $10,5 \pm 13,9$ \\
Altura da papila (cm) & $0,5 \pm 0,2$ & $0,4 \pm 0,2$ & $0,3 \pm 0,1$ \\
Largura da papila (cm) & $1 \pm 0,8$ & $1 \pm 1$ & $0,7 \pm 0,5$ \\
Circunferência da base & $4,8 \pm 4,5$ & $4,5 \pm 4,7$ & $3,9 \pm 4$ \\
da papila (cm) & & &
\end{tabular}

a Glândulas mamárias abdominais craniais (GMACr); ${ }^{\text {b }}$ Glândulas mamárias abdominais caudais (GMAC); ' Glândulas mamárias inguinais (GMI
Bellatini et al. (2010) cita que os alvéolos glândulas no mão pelada, apresentavam células secretoras cubica, em intensa atividade mitótica, em nossos estudos com o quati estas células apresentavam núcleo grande e redondo, citoplasma glandular e encontrava-se apoiada sobre uma camada delgada, formando o epitélio cuboide. Também notamos que nos animais não lactantes, estas glândulas estavam hipotrofiadas.

No quati as papilas mamárias possuía uma região ricamente vascularizada e com a presença fibras musculares lisas circulares e transversas, sendo que a sua maioria estavam localizadas abaixo do epitélio queratinizado, rode- 
ando os ductos papilares, igualmente relatado por Gurtler et al. (1987); Santos (2000) e Santos et al. (2007) em cães. Porém, no quati estas fibras musculares não circundavam cada óstio.

Por fim comparamos os tamanhos das papilas mamárias de seis fêmeas de Nasua nasua lactantes e não lactantes, assim no animal lactante houve aumento nos parâmetros mensurados, e isto pode estar relacionado, ao aumento das secreções hormonais de prolactina, estrógeno, progesterona e somatotrofina (Park \&Jacobson, 1993). Este aumento também foi relatado por Pinto et al. (2012) nas glândulas mamarias de felinos domésticos.

\section{CONCLUSÕES}

As glândulas mamarias das fêmeas de Nasua nasua são semelhantes quanto as características morfológicas dos animais domésticos e dos animais pertencentes à mesma Família, Procionidae.

Entretanto diferem-se dos animais domésticos em número e arquitetura microscópica, já dos animais da mesma Família somente no formato papilar.

Agradecimento.- À Fundação de Amparo à Pesquisa do Estado de São Paulo (FAPESP)

\section{REFERÊNCIAS}

Arce R.D. \& Flechtmann C.H.W. 1979. Introdução à Anatomia e Fisiologia Animal. Nobel, São Paulo. 300p.

Banks W.J. 1992. Histologia Veterinária Aplicada. 2ª ed. Manole, São Paulo. 629 p.

Behmer O.A. 1976. Manual de Técnicas para Histologia Normal e Patológica. Manole, São Paulo. 241p.

Beisiegel B.M. 2001. Notes on the coati, Nasua nasua (Carnivora: Procyonidae) in Atlantic Forest area. Braz. J. Biology 61:689-692.

Bellatine T., Mançanares C.A.F., Franciolli A.L.R., Ambrósio C.E., Martins D.S., Miglino M.A. \& Carvalho A.F. 2010. Estudo morfofuncional das glândulas mamárias de mão-pelada, Procyon cancrivorus. Pesq. Vet. Bras. 30:689-695.

Chamness G.C., Asch R.H. \& Pauerstein C.J. 1980. Danazol binding and translocation of steroid receptors. Am. J. Obstet. Gynecol. 136:426-429.

Chandra S.A., Cline J.M. \& Adler R.R. 2010. Cyclic morphological changes in the beagle mammary gland. Toxicologic. Pathol. 38:969-983.

Cowan P.E. 1989. Changes in milk composition during lactation in the commom brushtail possum, Trichosurus vulpecula (Marsupilis: Phalgeridae). Reprod. Fertil. Develop. 1:325-335.

Dyce K.M., Sack W.O. \& Wensing C.J.G. 1997. Tratado de Anatomia Veterinária. $2^{\mathrm{a}}$ ed. Guanabara Koogan, Rio de Janeiro. 663p.

Ellenport C.R. 1986. Aparelho urogenital do carnívoro, p.1481-1493. In: Getty R. (Ed.), Sisson/Grossman - Anatomia dos Animais Domésticos. 5a ed. Guanabara Koogan, Rio de Janeiro. 1445p.

Favaron P.O., Mançanares C.A.F., Ambrosio C.E., Leise R. \& Miglino M.A. 2008. Gross and Microscopic Anatomy of the Pineal Gland in Coati (Linnaeus, 1766). Anat. Histol. Embryol. 37:464-468.

Gompper M.E. 1995. Nasua narica. Mammalian Species 487:1-10

Gompper M.E. 2004. Correlations of Coati (Nasua narica) social structure with parasitism by ticks and chiggers, p.527-534. In: Sanchez-Cordeiro V. \& Medellin R.A. (Eds), Contribuciones Mastozoológicas en Homenaje a Bernardo Villa. Instituto de Biologia e Instituto de Ecologia UNAM, Cidade do México. 680p.

Guerrits P.O. 1983. Staining procedures for tissues embedded in 2-ydroxyetry metacrilate. Mikroskopie 5:321-328.
Gürtler H., Ketz H.A., Kol E., Schoröder L. \& Seidel H. 1987. Fisiologia Veterinária. 4a ed. Guanabara Koogan, Rio de Janeiro. 612p.

Humphrey L.J. \& Estes N.C. 1979. Aspects of fibrocystic disease of the breast: treatment with danazol. Postgrad. Med J. 5:48-51.

Jainudeen M.R. \& Hafez E.S.E. 1988. Gestação, Fisiologia Pré-Natal e Parto. Reprodução Animal. 4⿳亠丷a ed. Manole, São Paulo. 280p.

Junqueira L.C. \& Carneiro J. 2004. Histologia Básica. 10ª ed. Guanabara Koogan, Rio de Janeiro. 488p.

Junqueira L.C.V., Bignonas G. \& Bretan R.P. 1979. Picrosirius staining plus polarization microscopy, a specific method for collagen detection in the tissue sections. Histochem. J. 11:447-255.

Lillie R.D. \& Fulmer H.M. 1976. Histopathologic Technique and Practical Histochemistry. 4⿳亠丷厂 ed. McGraw-Hill, Universidade da Califórnia. 300p.

Luiz C.R., Oliveira K.M., Balestra R.A.M., Nascimento D.S. \& Ferreira J.R. 2004. Estudo comparativo da irrigação da papila mamária em cães sem raça definida (Canis familiaris Linnaeus, 1758). Braz. J. Vet. Res. Anim. Sci. 41(1):20-24.

Mies-Filho A. 1982. Reprodução dos Animais e Inseminação Artificiais. 5aㅗ ed. Sulina, Porto Alegre. 335p.

Orr R.T. 1986. Biologia dos Vertebrados. 5a ed. Roca, São Paulo. 508p.

Park C.S. \& Jacobson N.L. 1993. Glândula mamária e lactação, p.856. In: Swenson M.J. \& Reece W.O. (Eds), Fisiologia dos Animais Domésticos. $11^{a}$ ed. Guanabara Koogan, Rio de Janeiro.

Pieri N.C.G., Mançanares C.A.F., Bertassoli B., Lima J.M.N., Thomaz J.M. \& Carvalho A.F. 2011. Classificação morfofuncional dos dentes de quati, Nasua nasua. Pesq. Vet. Bras. 31(5):447-451.

Pinto J.N., Freitas L.A., Monteiro B.L.C., Pereira B.S., Silva H.V.M. \& Silva L.D.M. 2012. Avaliação ultrassonográfica bidimensional da glândula mamária felina durante a gestação e pós-parto. Anais VI Congresso Norte Nordeste de Reprodução Animal, Fortaleza, CE, p.523. (Resumo)

Polyak K. \& Hu M. 2005. Do myoepithelial cells hold the key for breast tumor progression? J. Mammary Gland Biol. Neoplasia10(3):231-247.

Queiroga F. \& Lopes C. 2002. Tumores Mamários Caninos: pesquisa de novos fatores de prognóstico. Revta Port. Ciênc. Vet. 97:119-127.

Ramalho L.N.Z., Ribeiro-Silva A., Cassali G.D. \& Zucoloto S. 2006. The expression of p63 and cytokeratin 5 in mixed tumors of the canine mammary gland provides new insights into the histogenesis of these neoplasms. Vet. Pathol. 43(4):424-429.

Ramalho L.N.Z., Ribeiro-Silva A., Cassali G.D. \& Zucoloto S. 2006. A expressão da p63 e citoqueratina 5 em tumores mistos da glândula mamária canina fornece novos insights sobre a histogênese dessas neoplasias. Patol. Vet. 43:424-429.

Rehm S., Stanislaus D.J., Williams A.M. 2007. Estrous cycle-dependent histology and review of sex steroid receptor expression in dog reproductive tissues and mammary gland and associated hormone levels. Birth Defects Res. B Dev. Reprod. Toxicol. 80:233-245.

Rocha E.C. \& Dalponte J.C. 2006. Composição e caracterização da fauna de mamíferos de médio e grande porte em uma pequena reserva de cerrado em Mato Grosso, Brasil. Revta Árvore 30:669-677.

Russel S.K. 1996. Teming of reproduction by coati (Nasua narica) in relation to fluctuations in food resources, p.413-431. In: Lugh E.G., Rand A.S. \& Windson D.M. (Eds), The Ecology of a Tropical Forest. $2^{\text {nd }}$ ed. Smithsonian Institution Press, Washington, DC.

Samoto V.Y., Miglino M.A., Ambrósio C.E., Pereira F.T.V., Lima M.C. \& Carvalho A.F. 2006. Morfologia da glândula mamária de gambás da espécie Didelphis sp associada ao modelo marsupial. Biota Neotrop. 6(2):1-12.

Santos D.A.S., Ricci R.E.G., Prado I.M.M., Carvalho A.F., Bombonato P.P., Ambrósio C.E., Teixeira D.G., Santos T.C., Hernandes-Brazquez F.J., Martins D.S., Morini A.C., Kfoury Jr J.R. \& Miglino M.A. 2007. Morfologia e morfometria das papilas mamárias de búfalas. Pesq. Vet. Bras. 27(3): 95-102.

Santos M., Marcos R. \& Faustino A.M. 2010. Histological study of canine mammary gland during the Oestrous cycle. Reprod. Domest. Anim. 45(5):146-154. 
Schedin P., Mitrenga T. \& Kaeck M. 2000. Estrous cycle regulation of mammary epithelial cell proliferation, differentiation, and death in the SpragueDawley rat: a model for investigating the role of estrous cycling in mammary carcinogenesis. J. Mammary Gland. Biol. Neoplasia 2:211-225.

Shida J.Y., Gebrim L.H., Simões M.J., Baracat E.C. \& De Lima G.R. 2001. Morphological and morphometrical study of permanent estrus rat mammary gland treated with danazol. Revta Bras. Ginecol. Obstet. 23:41-45.

Silver I.A. 1966. The anatomy of the mammary gland of the dog and cat. J. Small Anim. Pract. 7:689-296.

Sorenmo K.U., Rasotto R., Zappulli V. \& Goldschmidt M.H. 2011. Development, anatomy, histology, lymphatic drainage, clinical features, and cell differentiation markers of canine mammary gland neoplasms. Vet. Pathol. 48(1):85-97.

Tolosa E.M.C., Rodrigues C.J., Behmer O. \& Freitas Neto A.G. 2003. Manual de Técnicas para Histologia Normal e Patológica. $2^{\underline{a}}$ ed. Manole, São Paulo. 331p.

Urashima T., Yamamoto M., Nakamura T., Arai I., Saito T., Namiki M., Yamaoka K. \& Kawahara K. 1999. Chemical characterissation of the oligosaccharides in a sample of milk of a whitw-nosed coati, Nasua narica (Procyonidae: carnívora). Comp. Biochem. Physiol., Mol. Integr. Physiol. 123:187-193.

Zeller U. 1999. Mammalian reproduction: origin and evolutionary transformations. Zoologischer Anzeiger 238:117-130. 